\title{
Crescimento de Stylosanthes cv. Campo Grande em diferentes níveis de densidade de um Latossolo Vermelho ${ }^{1}$
}

\author{
Growth of Stylosanthes cv. Campo Grande at different density levels of an Oxisol
}

\author{
Deise Dalazen Castagnara ${ }^{2 *}$, Tiago Zoz ${ }^{3}$, Ana Maria Conte e Castro ${ }^{4}$, André Zoz ${ }^{2}$ e Paulo Sergio Rabello de \\ Oliveira $^{2}$
}

\begin{abstract}
RESUMO - O Stylosanthes spp. cv. Campo Grande é uma leguminosa recomendada para a recuperação de áreas de pastagens degradadas, entretanto são escassas as informações sobre seu desenvolvimento em solos compactados. Assim, objetivou-se com o presente trabalho avaliar o desenvolvimento do Stylosanthes cv. Campo Grande em diferentes níveis de densidade de um Latossolo Vermelho eutroférrico (LVef). O experimento foi desenvolvido no período entre setembro de 2007 e março de 2008, em cultivo protegido. O delineamento experimental utilizado foi inteiramente casualizado. Os tratamentos consistiram de cinco níveis de compactação do solo em sub-superfície $\left(1,0 ; 1,2 ; 1,4 ; 1,6\right.$ e $\left.1,8 \mathrm{Mg} \mathrm{m}^{-3}\right)$ com quatro repetições. As unidades experimentais foram compostas por vasos montados a partir de anéis de PVC sobrepostos. No solo estudado (LVef) o máximo crescimento do Stylosanthes cv. Campo Grande ocorre com a densidade de solo em torno de 1,27 $\mathrm{Mg} \mathrm{m}^{-3}$; e densidades de solo acima de 1,00 $\mathrm{Mg} \mathrm{m}^{-3}$ limitam o desenvolvimento radicular desta leguminosa.
\end{abstract}

Palavras-chave: Estilosantes. Solos-compactação. Sistema radicular.

\begin{abstract}
Stylosanthes spp. cv. Campo Grande is a legume recommended for the recovery of degraded areas of pasture, however there is little information about its development in compacted soils. The aim of the present study therefore was to evaluate the development of Stylosanthes cv. Campo Grande at different density levels of a eutroferric Oxisol (LVef). The experiment was carried out in a greenhouse from September 2007 to March 2008. Experimental design was completely randomized, and treatments consisted of five levels of sub-surface soil compaction (1.0, 1.2, 1.4, 1.6 and $\left.1.8 \mathrm{Mg} \mathrm{m}^{-3}\right)$ with four replications. The experimental units were pots made from overlapping PVC rings. In the soil under study (LVef), maximum growth of Stylosanthes cv. Campo Grande occurs at a soil density of around $1.27 \mathrm{Mg} \mathrm{m}^{-3}$; soil densities above $1.00 \mathrm{Mg} \mathrm{m}^{-3}$ limit the root development of this legume.
\end{abstract}

Key words: Stylosanthes. Soil compaction. Root system.

\footnotetext{
*Autor para correspondência

${ }^{1}$ Recebido para publicação em 16/08/2011; aprovado em 09/11/2012

Pesquisa Financiada pela Universidade Estadual do Oeste do Paraná

${ }^{2}$ Universidade Estadual do Oeste do Paraná, Rua Pernambuco 1777, Centro, Marechal Cândido Rondon-PR, Brasil, 85.960-000, deisecastagnara@ yahoo.com.br; andre_zoz@hotmail.com; rabello.oliveira@hotmail.com

${ }^{3}$ Universidade Estadual Paulista/Faculdade de Ciências Agrárias, Rua José Barbosa de Barros 1780, Botucatu-SP, Brasil, 18.610-307, tiago_ zoz@hotmail.com

${ }^{4}$ Universidade Estadual do Norte Paranaense, Rodovia BR 369, Km 54, Vila Maria, Bandeirantes-PR, Brasil, 86.360-000, acastro@uenp.edu.br
} 


\section{INTRODUÇÃO}

A habilidade das plantas em absorver água e nutrientes depende da distribuição de raízes no perfil do solo, a qual é função de reduzidas limitações físicas e químicas, as quais são passíveis de alterações pelas práticas de manejo do solo (ALVARENGA; CRUZ, 2003).

Dentre as características que interferem no desenvolvimento das plantas e que são profundamente alteradas pelo manejo adotado têm-se a compactação do solo. De acordo com Tavares Filho et al. (2001), a compactação reduz a porosidade do solo, a continuidade dos poros e a disponibilidade de água e nutrientes, reduzindo também o crescimento e o desenvolvimento radicular das culturas.

Em áreas de pastagem sob exploração intensiva, é comum a ocorrência de compactação do solo, pois a pressão do casco dos animais sobre o solo pode comprometer a qualidade física na camada superficial, em razão do aumento da densidade do solo e da redução da porosidade (GIAROLA; TORMENTA; DUTRA, 2007). A densidade está entre as propriedades físicas mais utilizadas na quantificação da qualidade física do solo, a qual é mais afetada nos primeiros $150 \mathrm{~mm}$ de profundidade (LANZANOVA et al., 2007).

Para evitar a compactação ou para minimizá-la pode-se adotar o cultivo de culturas que possuam sistema radicular profundo e com grande volume, capaz de promover a formação de canais (CARDOSO et al., 2003) e incorporar resíduos culturais ao solo melhorando sua estruturação (SANTOS; SALCEDO; GALVÃO, 2008).

O Stylosanthes spp. cv. Campo Grande foi obtido pela Embrapa Gado de Corte a partir de uma mistura física de sementes de Stylosanthes capitata e Stylosanthes macrocephala (VERZIGNASSI, 2007). Devido ao seu hábito de crescimento vigoroso e sistema radicular profundo, podendo atingir até $1,5 \mathrm{~m}$ (VERZIGNASSI, 2007), constituise uma alternativa para a melhoria da estruturação do solo, reduzindo perdas por erosão (DEDECEK; GALDINO; VIEIRA, 2006), e contribuindo para a descompactação do solo (NEGREIROS NETO et al., 2010).

Em sistema de consórcio, seu melhor desempenho foi observado em solos com teores de argila menores que $15 \%$, com desenvolvimento satisfatório naqueles com até $35 \%$ de argila. Em solos argilosos e com alta fertilidade, seu desenvolvimento não é satisfatório devido à competição com as gramíneas consorciadas, que se desenvolvem mais vigorosamente nessas condições (VERZIGNASSI, 2007).

Em cultivo solteiro são escassas as informações disponíveis sobre o Stylosanthes cv. Campo Grande, especialmente em solos argilosos sob compactação. Entretanto, maiores conhecimentos sobre a adaptação das espécies leguminosas às condições edafoclimáticas da região onde serão introduzidas é essencial para garantir o êxito de sua implantação (TEODORO et al., 2011). Dessa forma, objetivou-se com o presente trabalho avaliar o desenvolvimento da parte aérea e do sistema radicular do Stylosanthes cv. Campo Grande em um Latossolo Vermelho submetido às diferentes densidades.

\section{MATERIAL E MÉTODOS}

O experimento foi desenvolvido no período de 29 de setembro de 2007 a 04 de março de 2008, em cultivo protegido pertencente ao Centro de Ciências Agrárias da Universidade Estadual do Oeste do Paraná, Campus de Marechal Cândido Rondon-PR.

Como substrato para o crescimento das plantas foi utilizado um Latossolo Vermelho eutroférrico (LVef) (EMPRESA BRASILEIRA DE PESQUISA AGROPECUÁRIA, 2006), coletado em área agrícola na camada de $0-20 \mathrm{~cm}$. Após secagem à sombra e passado em peneira de $5 \mathrm{~mm}$ de malha fez-se uma amostragem para determinação das características químicas: $\mathrm{pH}\left(\mathrm{em} \mathrm{H}_{2} \mathrm{O}\right)=$ 5,29; Al trocável $\left(\mathrm{cmol} \mathrm{dm}^{-3}\right)=0,00 ; \mathrm{Ca}^{+2}\left(\mathrm{cmol} \mathrm{dm}^{-3}\right)=$ 6,69; $\mathrm{Mg}^{+2}\left(\mathrm{cmol}_{\mathrm{c}} \mathrm{dm}^{-3}\right)=1,48 ; \mathrm{P}-$ Mehlich $1\left(\mathrm{mg} \mathrm{dm}^{-3}\right)=$ 25,$64 ; \mathrm{K}\left(\mathrm{cmol}_{\mathrm{c}} \mathrm{dm}^{-3}\right)=1,02 \mathrm{cmol}_{\mathrm{c}} \mathrm{dm}^{-3}$; Matéria orgânica $\left(\mathrm{g} \mathrm{dm}^{-3}\right)=32,81 ; \mathrm{H}+\mathrm{Al}$ (acetato de cálcio 0,5 $\left.\mathrm{mol} \mathrm{L}^{-1}\right)$ : $4,14 \mathrm{cmol} \mathrm{dm}^{-3}$; Soma de bases $\left(\mathrm{cmol}_{\mathrm{c}} \mathrm{dm}^{-3}\right)=9,19 ; \mathrm{V}$ $(\%)=68,94 \%$; argila $=856,80 \mathrm{~g} \mathrm{~kg}^{-1}$, silte $=73,40 \mathrm{~g} \mathrm{~kg}^{-1}$ $\mathrm{e}$ areia $=69,80 \mathrm{~g} \mathrm{~kg}^{-1}$ (EMPRESA BRASILEIRA DE PESQUISA AGROPECUÁRIA, 1997).

Odelineamentoexperimental utilizadofoi inteiramente casualizado. Os tratamentos consistiram de cinco níveis de compactação do solo $\left(1,0 ; 1,2 ; 1,4 ; 1,6\right.$ e 1,8 $\left.\mathrm{Mg} \mathrm{m}^{-3}\right)$ com quatro repetições, totalizando 20 unidades experimentais. Foram realizados dois cortes para a avaliação do Stylosanthes cv. Campo Grande ao longo do período experimental.

As unidades experimentais foram compostas por vasos montados a partir de anéis de PVC (policloreto de vinila) sobrepostos. Para confecção dos vasos foi utilizado o mesmo solo no anel superior, intermediário e inferior. Para obtenção das densidades em estudo utilizou-se um conjunto compactador composto por um círculo de madeira de diâmetro ligeiramente inferior aos anéis, composto por uma haste de ferro com massa de aproximadamente 7,2 kg lançado de uma determinada altura, por quantas vezes fosse necessário para acomodar uma massa conhecida de solo em um anel de volume conhecido, proporcionando a compactação desejada, segundo os tratamentos. O anel compactado $(3,5 \mathrm{~cm})$ foi unido aos demais anéis 
[superior $(12 \mathrm{~cm})$ e inferior $(35 \mathrm{~cm})]$ por fita adesiva, com uma pequena faixa dobrada internamente, para evitar a passagem de raízes que eventualmente encontrassem menor resistência à penetração entre o solo e a parede do vaso, enquanto que nos anéis inferiores e superiores as densidades foram padronizadas para $1,0 \mathrm{Mg} \mathrm{m}^{-3}$. Na base do anel inferior foi acoplado um cap (tampa) dotado de cinco furos com diâmetro de $0,5 \mathrm{~mm}$ e revestido internamente por uma tela plástica com malha de $0,02 \mathrm{~m}$ visando a drenagem da água e limitando o desenvolvimento das raízes ao interior do vaso.

Para a semeadura do Stylosanthes cv. Campo Grande utilizaram-se 20 sementes por vaso e após 30 dias da semeadura foi realizado desbaste, permanecendo apenas quatro plantas por vaso. Decorridos 43 dias após a semeadura (DAS) foi realizada adubação de cobertura nas doses de $60 \mathrm{~kg} \mathrm{ha}^{-1}$ de nitrogênio na forma de uréia e $30 \mathrm{~kg} \mathrm{ha}^{-1}$ de potássio $\left(\mathrm{K}_{2} \mathrm{O}\right)$ na forma de cloreto de potássio.

Os cortes para as avaliações foram realizados aos 70 e 130 DAS respeitando-se o desenvolvimento vegetativo das plantas. Na mesma ocasião foi determinada a altura das plantas. As plantas foram cortadas com altura de $5 \mathrm{~cm}$ do solo com auxílio de tesoura de poda. Após o corte as plantas foram separadas em folhas e hastes e submetidas à secagem em estufa com ventilação de ar forçada a $55^{\circ} \mathrm{C}$ por 72 horas com posterior pesagem. A partir dos valores obtidos, foram calculadas a produção de matéria seca total, de folhas e de caules, e a relação folha/caule.

Após o segundo corte (130 DAS), os vasos foram desmontados e as raízes de cada anel foram separadas do solo com auxílio de peneiras, lavadas e submetidas à secagem em estufa com ventilação de ar forçada a $55^{\circ} \mathrm{C}$ por 72 horas e posteriormente pesadas. Foram obtidos a matéria seca de raiz no anel superior, no anel compactado (intermediário), no anel inferior, e a matéria seca total de raiz. A partir da matéria seca total de raiz e da parte aérea foi calculada a relação raiz/parte aérea.

Os dados obtidos em cada época de avaliação da parte aérea, bem como os obtidos para cada anel que compunha os vasos (superior, intermediário e inferior) e a produção total de matéria seca foram estudados separadamente. Não foram realizadas comparações entre as épocas de avaliação e entre as camadas de solo (anéis) para o sistema radicular. Assim, os dados foram submetidos à análise de variância e quando constatada significância pelo teste $\mathrm{F}$ ao nível de $5 \%$ de significância as médias referentes às densidades do solo foram submetidas à análise de regressão, considerando-se o maior coeficiente de determinação. Para a análise dos dados utilizou-se o programa SISVAR (FERREIRA, 2008).

\section{RESULTADOS E DISCUSSÃO}

A densidade do solo apresentou influência sobre a altura de planta do Stylosanthes cv. Campo Grande no primeiro e no segundo corte, enquanto para a massa seca da parte aérea, massa seca de folhas, massa seca de haste e relação folha/haste houve significância das densidades apenas no segundo corte (Tabela 1).

A máxima altura é estimada com a densidade de solo de $1,26 \mathrm{Mg} \mathrm{m}^{-3}$ e $1,27 \mathrm{Mg} \mathrm{m}^{-3}$ para o primeiro e segundo corte respectivamente (Figura 1a). Esses resultados confirmam a sensibilidade do Stylosanthes cv. Campo Grande à compactação do solo especialmente em solos argilosos, pois a cultivar é adaptada a solos pobres e arenosos. Reichert, Reinert e Braida (2003), sugeriram valores críticos de densidade para solos de textura muito argilosa variando entre 1,25 e $1,30 \mathrm{Mg} \mathrm{m}^{-3}$, e Folloni, Lima e Bull (2006), observaram redução no crescimento de leguminosas [mucuna preta (Mucuna aterrima Pipper e Tracy) e labe labe (Dolichos lab lab L.)] cultivadas em solo de textura argilosa (Nitossolo eutrófico).

Ao estudarem a produção de matéria seca da parte aérea do guandu [Cajanus cajan (L.) Mill sp.], guandu anão [Cajanus cajan (L.) Mill sp., variedade anão] e da crotalária juncea (Crotalaria juncea L.) em apenas uma avaliação 60 DAS, Folloni, Lima e Bull (2006) também não observaram efeito da compactação subsuperficial sobre a produção de massa seca.

Tabela 1 - Resumo da análise de variância da parte aérea do Stylosanthes cv. Campo Grande no primeiro e no segundo corte em diferentes níveis de densidades de um Latossolo Vermelho

\begin{tabular}{lll}
\hline \multirow{2}{*}{ Variáveis } & \multicolumn{2}{c}{ Valores de F calculado } \\
\cline { 2 - 3 } & $1^{\circ}$ corte & $2^{\mathrm{o}}$ corte \\
\hline Altura de planta & $0,0210^{*}$ & $0,000^{* *}$ \\
Massa seca da parte aérea & $0,4175^{\mathrm{ns}}$ & $0,000^{* *}$ \\
Massa seca de folhas & $0,6629^{\mathrm{ns}}$ & $0,000^{* *}$ \\
Massa seca de hastes & $0,2143^{\mathrm{ns}}$ & $0,000^{* *}$ \\
Relação folha/haste & $0,3427^{\mathrm{ns}}$ & $0,000^{* *}$ \\
\hline
\end{tabular}

ns não significativo; **;* significativo ao nível de $1 \%$ e a $5 \%$ pelo teste $\mathrm{F}$, respectivamente 
Já no segundo corte, o máximo acúmulo de matéria seca de parte aérea, de folhas e de haste foi verificado com as densidades de solo de 1,28 $\mathrm{Mg} \mathrm{m}^{-3}$ (Figura 1b), 1,29 $\mathrm{Mg} \mathrm{m}^{-3}$ (Figura 1c) e 1,28 $\mathrm{Mg} \mathrm{m}^{-3}$ (Figura 1d), respectivamente.
Diferenças entre as densidades eram esperadas, pois as condições físicas do solo são determinantes no desenvolvimento das plantas (BOTTEGA et al., 2011). O maior acúmulo de massa seca nas densidades citadas se

Figura 1 - Altura de planta (a), massa seca da parte aérea (b), massa seca de folhas (c), massa seca de haste (d) e relação folha/haste (e) do Stylosanthes cv. Campo Grande em diferentes níveis de compactação de um Latossolo Vermelho
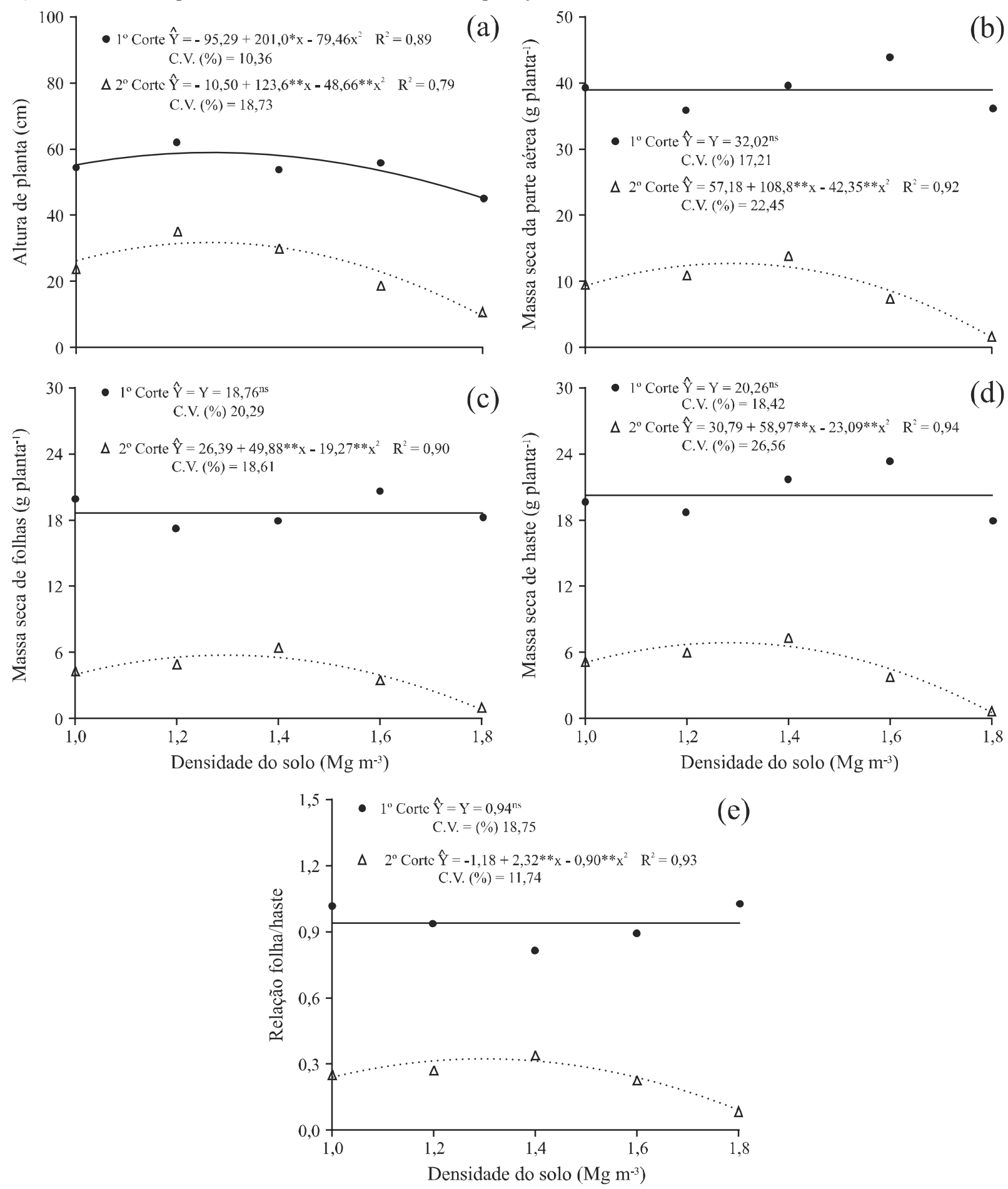

${ }^{\text {ns }}$ não significativo; $* * \mathrm{e} *$ significativo a $1 \%$ e $5 \%$ 
deve ao fato de que em níveis intermediários de densidade do solo pode ocorrer maior contato entre o solo e a raiz, promovendo melhores condições de absorção de água e nutrientes, sem prejudicar drasticamente o crescimento das raízes (MÜLLER; CECCON; ROSOLEM, 2001). Os decréscimos observados no acúmulo de massa seca a partir das densidades estudadas se devem à deficiência de aeração para as raízes, que em Latossolo Vermelho argiloso se inicia com densidades do solo próximas à $1,30 \mathrm{Mg} \mathrm{m}^{-3}$ (ARGENTON et al., 2005).

As diferenças na produção de massa seca do primeiro para o segundo corte estão relacionadas com a ocupação do espaço acima da camada compactada pelas raízes do Stylosanthes cv. Campo Grande. No primeiro corte, o volume radicular que se desenvolveu era reduzido, e como as raízes eram jovens e com grande capacidade de absorção (TAIZ; ZEIGER, 2009), as plantas desenvolveram-se normalmente em todas as densidades estudadas, mesmo que as plantas conseguissem explorar somente o solo acomodado no anel superior nos vasos. Com a realização do corte, as primeiras raízes emitidas pelas plantas encontravam-se lignificadas, e apesar de o corte ter estimulado a emissão e desenvolvimento de novas raízes, o crescimento das mesmas foi prejudicado pela presença da camada compactada de solo, reduzindo consequentemente o desenvolvimento das plantas e o acúmulo de matéria seca. Zonetti et al. (2011), na cultura da soja, encontraram relação inversa entre o acúmulo de matéria seca e a lignificação do sistema radicular das plantas. Os resultados concordam com Fidalski et al. (2008), que consideram o comprometimento da qualidade física do solo como uma das causas da redução da produtividade das pastagens.

No segundo corte a máxima relação folha/haste foi constatada com a densidade de solo de $1,28 \mathrm{Mg} \mathrm{m}^{-3}$. O decréscimo da relação folha/haste está relacionado com a redução da área foliar do Stylosanthes cv. Campo Grande em resposta à compactação do solo. Em feijoeiro Guimarães, Stone e Moreira(2002), também trabalhando com Latossolo Vermelho observaram decréscimos na área foliar com densidades do solo acima de $1,2 \mathrm{Mg} \mathrm{m}^{-3}$.

A análise de variância individual em cada camada de solo (anel) revelou efeito significativo das densidades do solo sobre a massa seca das raízes, e também sobre a massa seca total de raízes (soma das três camadas) e a relação raiz/parte aérea (Tabela 2).

Nos anéis, superior, compactado (intermediário) e inferior ocorre decréscimo da matéria seca de raiz com o aumento na densidade do solo. O decréscimo ocorre de forma mais acentuada no anel superior, seguido pelo anel compactado (intermediário) que por sua vez é seguido pelo anel inferior (Figura 2a).
Tabela 2 - Resumo da análise de variância de raízes do Stylosanthes cv. Campo Grande em diferentes níveis de densidade de um Latossolo Vermelho

\begin{tabular}{|c|c|}
\hline Variáveis & Valores de F calculado \\
\hline MS-S & $0,0000 * *$ \\
\hline MS-C & $0,0007 * *$ \\
\hline MS-I & $0,0005^{* *}$ \\
\hline MSTR & $0,0001 * *$ \\
\hline RRPA & $0,0000 * *$ \\
\hline
\end{tabular}

MS-S - Massa seca de raiz na camada superior; MS-C - Massa seca de raiz na camada intermediária (compactada); MS-I - Massa de raiz na camada inferior; MSTR - Massa seca total de raiz; RRPA - Relação raiz/ parte aérea; ** significativo a $1 \%$ de significância pelo teste $\mathrm{F}$

O decréscimo da matéria seca da raiz se deve ao aumento das densidades do solo nas camadas compactadas, pois com o aumento das densidades, menos raízes conseguiram chegar e ultrapassar o anel intermediário e atingir o anel inferior. Com a exploração de um menor volume de solo, menor quantidade de nutrientes e água foram absorvidos, com consequente menor desenvolvimento da parte aérea das plantas. Segundo Silva, Maia e Bianchini (2006), a densidade da camada compactada capaz de limitar o crescimento das plantas varia conforme a classe de solo, condições de umidade, espécie e ou mesmo do cultivar plantado. Negreiros Neto et al. (2010) ao trabalharem com um Neossolo Quartzarênico Órtico (9\% de argila e 87\% de areia) e um Argissolo Vermelho Escuro eutroférrico (31\% de argila e $61 \%$ de areia), observaram que o Stylosanthes cv. Campo Grande contribuiu para a redução na compactação apenas no Neossolo.

A massa seca total de raiz foi reduzida linearmente com o aumento das densidades do solo (Figura 2b), sendo que para cada $0,2 \mathrm{Mg} \mathrm{m}^{-3}$ que aumenta na densidade do solo ocorre um decréscimo de $0,45 \mathrm{~g}$ de matéria seca total de raiz. Esse resultado revela que as raízes do Stylosanthes cv. Campo Grande apresentam pequena capacidade de penetrar e se desenvolver em camadas compactadas. Esse resultado é coerente com os observados para o desenvolvimento da parte aérea do Stylosanthes cv. Campo Grande (Figura 1), e concorda com Cubilla et al. (2002), que relatam que mesmo espécies indicadas para a descompactação do solo têm o desenvolvimento de suas raízes limitado quando o solo apresenta níveis elevados de densidade.

Para a relação raiz/parte aérea constatou-se o ponto de mínimo com a densidade do solo de $1,30 \mathrm{Mg} \mathrm{m}^{-3}$, a partir do qual ocorreu incremento na relação raiz/parte aérea (Figura 2c). Esse resultado reforça a sensibilidade do Stylosanthes cv. Campo Grande à compactação do 
Figura 2 - Massa seca de raiz no anel superior, no anel compactado e no anel inferior (a), matéria seca de raiz total (b) e relação raiz/ parte aérea (c) do Stylosanthes cv. Campo Grande em diferentes níveis de densidade de um Latossolo Vermelho
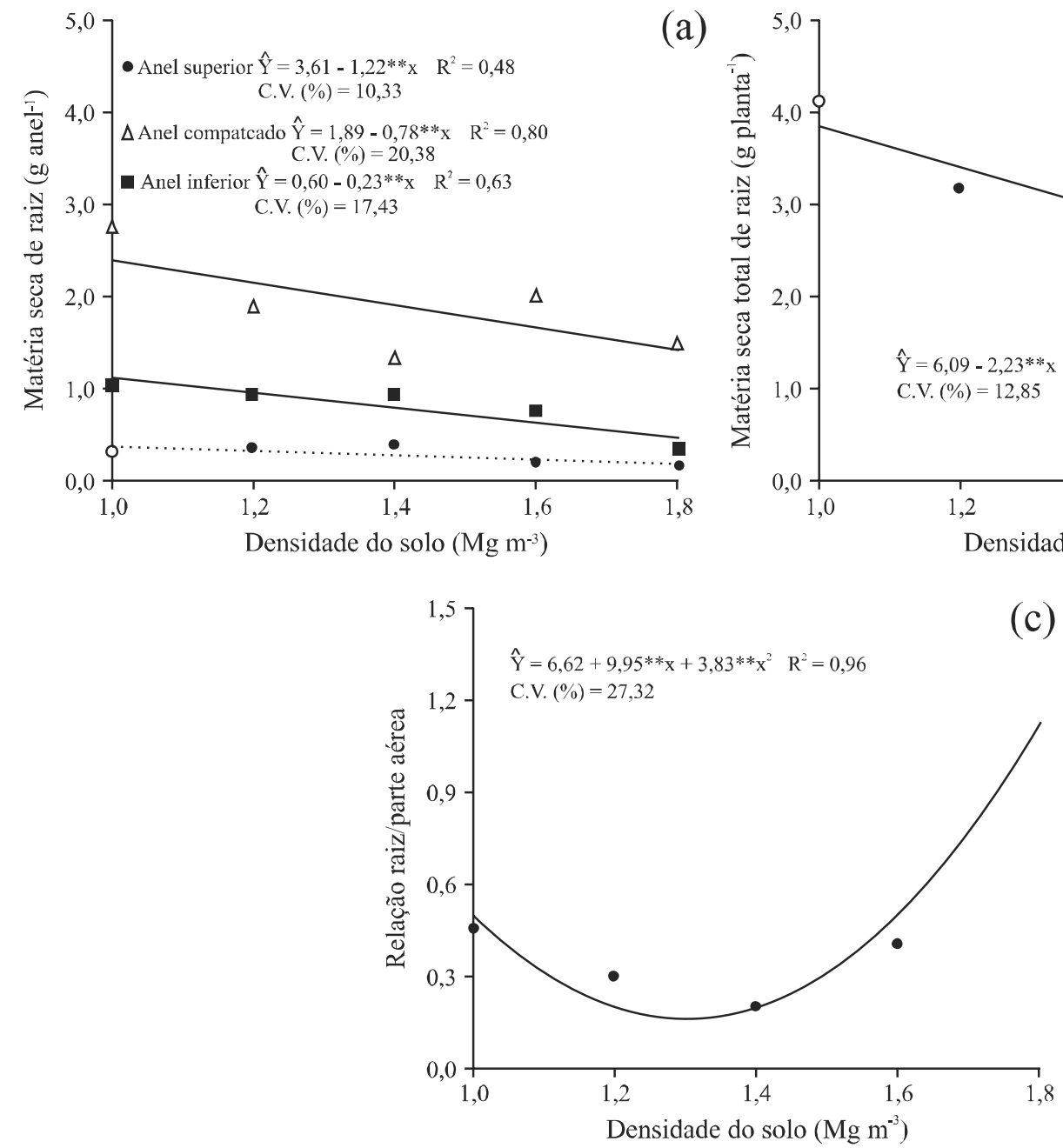

** significativo a $1 \%$

Figura 3 - Concentração de raízes de Stylosanthes cv. Campo Grande por camada de solo em diferentes níveis de densidade de um Latossolo Vermelho

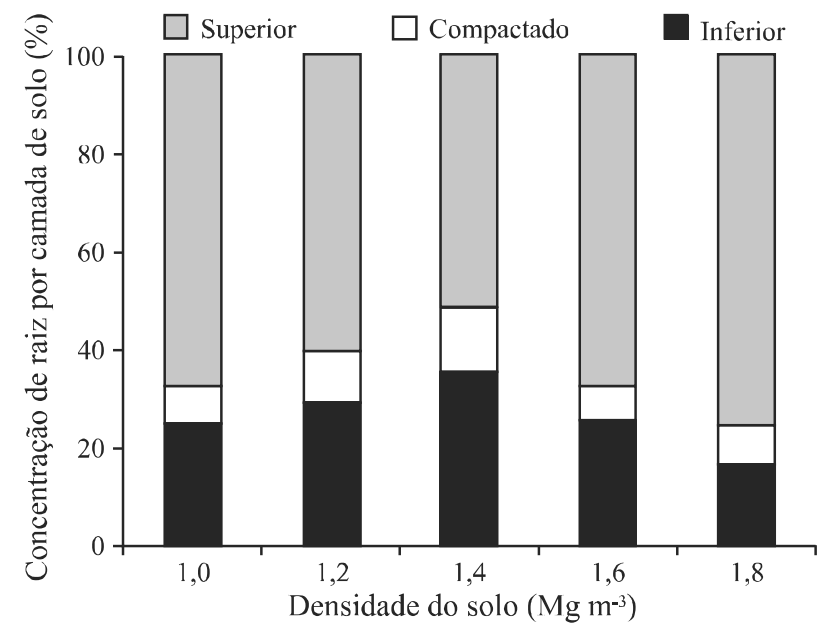

solo, pois o aumento da relação raiz/parte aérea indica que, mesmo havendo desenvolvimento radicular, a parte aérea foi sensivelmente afetada pela compactação.

A maior concentração de raiz no anel superior foi constatada na maior densidade de solo $\left(1,8 \mathrm{Mg} \mathrm{m}^{-3}\right)$. Esse resultado era esperado, e deve-se ao impedimento mecânico imposto ao desenvolvimento das raízes pelo anel com solo compactado (intermediário) (Figura 3).

Também na maior densidade de solo foi verificada a menor concentração de raízes no anel inferior, devido à presença da camada compactada que não foi rompida pelas raízes do Stylosanthes cv. Campo Grande (Figura 3). Por meio de metodologia similar e também trabalhando com Latossolo Vermelho, Jimenez et al. (2008) obtiveram resultados semelhantes para o desenvolvimento do guandu. (b)

(c)
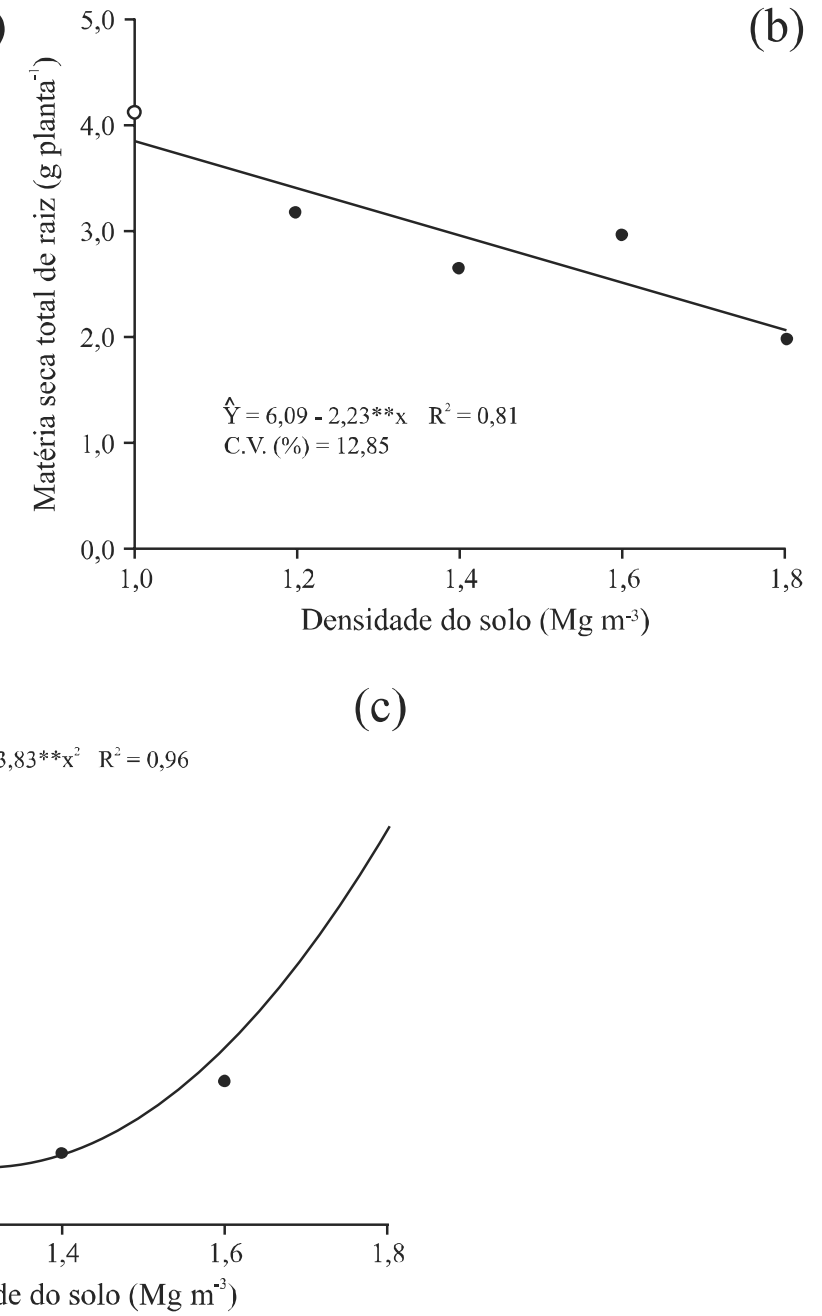


\section{CONCLUSÕES}

1. O máximo crescimento da parte aérea do Stylosanthes cv. Campo Grande ocorre com a densidade de solo aproximada de $1,27 \mathrm{Mg} \mathrm{m}^{-3}$;

2. Densidades de solo acima de $1,00 \mathrm{Mg} \mathrm{m}^{-3}$ limitaram o desenvolvimento radicular do Stylosanthes cv. Campo Grande cultivado em Latossolo Vermelho eutroférrico (LVef).

\section{REFERÊNCIAS}

ALVARENGA, R. C.; CRUZ, J. C. Manejo de solos e agricultura irrigada. In: RESENDE, M.; ALBUQUERQUE, P. E. P.; COUTO, L. (Ed.). A cultura do milho irrigado. Brasília: Embrapa informação tecnológica, 2003. p. 70-106.

ARGENTON J. et al. Comportamento de atributos relacionados com a forma da estrutura de Latossolo Vermelho sob sistemas de preparo e plantas de cobertura. Revista Brasileira de Ciência Solo, v. 29, n. 3, p. 425-435, 2005.

BOTTEGA, E. L. et al. Variabilidade espacial da resistência do solo à penetração em um Latossolo Vermelho distroférrico. Revista Brasileira de Ciências Agrárias, v. 6, n. 2, p. 331-336, 2011.

CARDOSO, E. G. et al. Distribuição do sistema radicular da cultura da soja em função do manejo do solo. In: CONGRESSO BRASILEIRO DE CIÊNCIA DO SOLO, 29., 2003, Ribeirão Preto. Anais... Ribeirão Preto: Sociedade Brasileira de Ciência do Solo, 2003. 1 CD-ROM.

CUBILLA, M. et al. Plantas de cobertura do solo: uma alternativa para aliviar a compactação em sistema plantio direto. Revista Plantio Direto, v. 71, p. 29-32, 2002.

DEDECEK, R. A.; GALDINO, S.; VIEIRA, L. M. Perdas de solo e água em pastagens cultivadas em solo arenoso da Bacia do Alto Taquari, MS. Corumbá: Embrapa Pantanal; [Colombo]: Embrapa Florestas, 2006. 1 Folder.

EMPRESA BRASILEIRA DE PESQUISA AGROPECUÁRIA. Sistema brasileiro de classificação de solos. 2 . ed. Rio de Janeiro: Embrapa Solos, 2006. 306 p.

EMPRESA BRASILEIRA DE PESQUISA AGROPECUÁRIA - EMBRAPA. Centro Nacional de Pesquisa do Solo. Manual de métodos de análise de solo. 2.ed. Rio de Janeiro: Embrapa Solos, 1997. 212 p.

FERREIRA, D.F. SISVAR: um programa para análises e ensino de estatística. Revista Científica Symposium, v. 6, n. 2 , p. $36-41,2008$

FIDALSKI, J. et al. Qualidade física do solo em pastagem adubada e sob pastejo contínuo. Pesquisa Agropecuária Brasileira, v. 43, n. 11, p. 1583-1590, 2008.

FOLLONI, J. S. S.; LIMA, S. L. de; BULL, L. T. Crescimento aéreo e radicular da soja e de plantas de cobertura em camadas compactadas de solo Revista Brasileira de Ciência do Solo, v. 30, n. 1 , p. 49-57, 2006.

GIAROLA, N. F. B.; TORMENA, C. A.; DUTRA, A. C. Degradação física de um Latossolo Vermelho utilizado para produção intensiva de forragem. Revista Brasileira de Ciência do Solo, v. 31, n. 5, p. 863-873, 2007.

GUimarÃES, C. M.; STONE, L. F.; MOREIRA, J. A. A. Compactação do solo na cultura do feijoeiro. II: efeito sobre o desenvolvimento radicular e da parte aérea. Revista Brasileira de Engenharia Agrícola e Ambiental, v. 6, n. 2, p. 213-218, 2002.

JIMENEZ, R. L. et al. Crescimento de plantas de cobertura sob diferentes níveis de compactação em um Latossolo Vermelho. Revista Brasileira de Engenharia Agrícola e Ambiental, v. 12, n. 2, p. 116-121, 2008.

LANZANOVA, M. E. et al. Atributos físicos do solo em sistema de integração lavoura-pecuária sob plantio direto. Revista Brasileira de Ciência do Solo, v. 31, n. 5, p. 1131-1140, 2007.

MÜLLER, M. M. L.; CECCON, G.; ROSOLEM, C. A. Influência da compactação do solo em subsuperfície sobre o crescimento aéreo e radicular de plantas de adubação verde de inverno. Revista Brasileira de Ciência do Solo, v. 25, n. 3, p. 531-538, 2001.

NEGREIROS NETO, J. V. et al. Atributos físicos de solos sob a consorciação gramíneas-leguminosas no norte do estado do Tocantins. Engenharia na Agricultura, v. 18, n. 2, p. 140-150, 2010.

REICHERT, J. M.; REINERT, D. J. BRAIDA, J. A. Qualidade dos solos e sustentabilidade de sistemas agrícolas. Ciência e Ambiente, v. 27, n. 2, p. 29-48, 2003.

SANTOS, A. C.; SALCEDO, I. H.; GALVAO, S. R. S. Relações entre uso do solo, relevo e fertilidade do solo em escala de microbacia. Revista Brasileira de Engenharia Agrícola e Ambiental, v. 12, n. 5, p. 458-464, 2008.

SILVA, G. J.; MAIA, J. C. S.; BIANCHINI, A. Crescimento da parte aérea de plantas cultivadas em vaso, submetidas a irrigação subsuperficial e a diferentes graus de compactação de um Latossolo Vermelho-Escuro distrófico. Revista Brasileira de Ciência do Solo, v. 30, n. 1, p. 31-40, 2006.

TAIZ, L.; ZEIGER, E. Fisiologia vegetal. 4. ed. Porto Alegre: Artmed, 2009. 819 p.

TAVARES FILHO, J. et al. Resistência do solo à penetração e desenvolvimento do sistema radicular do milho (Zea mays) sob diferentes sistemas de manejo em um Latossolo Roxo. Revista Brasileira de Ciência do Solo, v. 25, n. 3, p. 725-730, 2001.

TEODORO, R. B. et al. Leguminosas herbáceas perenes para utilização como coberturas permanentes de solo na Caatinga Mineira. Revista Ciência Agronômica, v. 42, n. 2, p. 292-300, 2011.

VERZIGNASSI, J. R. Cultivo e uso do estilosantes Campo Grande - COT 105. Campo Grande: Embrapa Gado de Corte, 2007. $11 \mathrm{p}$.

ZONETTI, P. C. et al. Growth and root lignification of susceptible and glyphosate-resistant soybean. Acta Scientiarun, Agronomy, v. 33, n. 2, p. 291-295, 2011. 